\title{
SISTEM INFORMASI PENDAFTARAN E-RAPORT DAN PRESTASI SISWA SDIT DAARUL FATAA
}

\author{
Akbar ‘Asif Subagiyo', Suranto Saputra ${ }^{2}$, Gita Kencanawaty ${ }^{3}$ \\ ${ }^{1,2,3}$ Teknik Informatika, Fakultas Teknik dan Ilmu Komputer, Universitas Indraprasta PGRI Jakarta \\ Jalan Raya Tengah No 80, Kelurahan Gedong, Pasar Rebo, Jakarta Timur \\ 11akbarasiff@gmail.com,$\underline{2}$ surantounindra@yahoo.co.id, ${ }^{3}$ gitakencanawaty@informatikaunindra.org
}

\begin{abstract}
ABSTRAK
Di zaman modern ini manusia membutuhkan sistem berupa komputerisasi untuk mempermudah perkerjaan. Penelitian di SDIT Daarul Fataa, beralamat di Gg.Lurah Muda Blok Gapura No.40, RT.3/RW.3, Cimanggis, Kec. Bojong Gede, Bogor. Sistem yang dirancang berfungsi untuk membantu proses sistem informasi pendaftaran, absensi, penjadwalan, prestasi siswa dan e-raport di SDIT Daarul Fataa. Dengan adanya sistem komputerisasi maka sistem pendaftarannya tidak menggunakan formulir manual, raport yang ditulis manual dan sehingga sering terjadi keterlambatan dalam pemberian laporan rekapitulasinya, jadi pengelolaan datanya harus menggunakan sistem komputerisasi. Metode yang diterapkan adalah grounded research yaitu metodologi umum untuk mengembangkan suatu teori. Grounded research dapat disebut juga sebuah pendekatan yang refleksif dan terbuka, dimana pengumpulan data, pengembangan konsep-konsep teoritis dan ulasan literatur berlangsung dalam proses siklus berkelanjutan. Tujuan penelitian ini. Untuk meningkatkan sistem informasi pendaftaran, absensi dan raport sebagai pengembangan yang masih manual. Membuat sistem pendaftaran, absensi dan raport secara komputerisasi agar lebih efektif dan efisien. Membuat rekapitulasi pendaftaran, absensi dan raport yang lebih cepat. Hasil Akhir dari penelitian ini terbuat sebuah rancangan program sistem informasi pendaftaran, e-raport, prestasi siswa, menggunakan database dan berbentuk sebuah program berbasis Java MySql.
\end{abstract}

Kata Kunci: Sistem Informasi, Pendaftaran, E-Raport, Prestasi Siswa

\begin{abstract}
In this modern era, humans need a computerized system to make work easier. Research at SDIT Daarul Fataa, having its address at Gg.Lurah Muda Blok Gapura No.40, RT.3/RW.3, Cimanggis, Kec. Bojong Gede, Bogor. The system designed serves to assist the process of registration, attendance, scheduling, student achievement and eraport information systems at SDIT Daarul Fataa. With the computerized system, the registration system does not use manual forms, report cards are written manually and so there are often delays in providing recapitulation reports, so data management must use a computerized system. The method applied is grounded research, which is a general methodology for developing a theory. Grounded research can also be called a reflexive and open approach, where data collection, theoretical concept development and literature review take place in a continuous cycle process. The purpose of this research. To improve the registration information system, attendance and report cards as a development that is still manual. Creating a computerized system of registration, attendance and report cards to be more effective and efficient. Make registration recapitulation, attendance and report cards faster. The final result of this research is a design of a registration information system program, e-report, student achievement, using a database and in the form of a Java MySql-based program.
\end{abstract}

Key Word: Information Systems, Registration, E-Report, Student Achievement

\section{PENDAHULUAN}

Sistem Informasi yang digunakan disekolah ini masih menggunakan tenaga manusia atau masih manual dan sudah terkomputerisasi tetapi masih standar pendataan yang digunakan menggunakan Microsoft Excel dan Microsoft Word jadi belum terlalu akurat dalam hal pengolahan datanya, dan kurang akuratnya pembuatan laporannya, disini penulis ingin membuat agar sistem disekolah ini terdapat penggunaan komputerisasi yang mudah, cepat, akurat dan efisien dalam melakukan pendataan, laporannya di SDIT Daarul Fataa. Pada penelitian ini telah dihasilkan sebuah sistem informasi pendaftaran, e-raport dan prestasi siswa yang dapat membantu dalam pendataan pendaftaran, absensi, nilai raport, prestasi siswa dan pembuatan laporannya. Tujuan penelitian ini. Untuk meningkatkan sistem informasi 
pendaftaran, absensi dan raport sebagai pengembangan yang masih manual. Membuat sistem pendaftaran, absensi dan raport secara komputerisasi agar lebih efektif dan efisien. Membuat rekapitulasi pendaftaran, absensi dan raport yang lebih cepat.

Pendaftaran merupakan suatu hal yang sangat penting, karena dengan adanya pendaftaran, maka hal yang berpengaruh pada kelancaran dan dalam melaksanakan pemprosesan pendaftaran. Pengertian pendaftaran disini, pada dasarnya hanya unutk memperlancar dan mempermudah dala proses pendaftaran siswa dan siswi baru, pendataan dan pembagian kelas siswa dan siswi , sehingga dapat terorganisir dengan baik .(Yulianti, 2017).

Pengertian penerimaan siswa baru dapat diartikan sebagai proses pendaftaran utuk menjadi siswa baru pada sekolah lama ke sekolah yang baru dengan beberapa tahap penyeleksian yang dilakukan oleh sekolah baru. Penerimaan siswa baru selalu dilakukan di setiap tahun ajaran baru oleh semua sekolah.(Utomo \& Ariyanti, 2014).

Nilai raport merupakan hasil kumpulan nilai mata pelajaran dimiliki setiapsiswa yang berisi laporan nilai selama satu semester. Rapor diterimakan sebagaitolak ukur dan untuk mengetahui perkembangan terhadap prestasi siswa setelah mengikuti proses pembelajaran.(Karim \& Purba, 2019).

Fungsi pokok evaluasi hasil belajar siswa secara umum adalah untuk mengukur tingkat kemajuan siswa dalam belajar, untuk menyusun rencana belajar selanjutnya dan untuk memperbaiki proses pembelajaran.(Widiyaningtyas, 2013).

Prestasi belajar merupakan "bukti keberhasilan yang telah dicapai oleh seseorang. Dengan demikian, prestasi belajar merupakan hasil maksimum yang dicapai oleh seseorang setelah melakukan usaha-usaha belajar".(Sutinah et al., 2018).

Prestasi merupakan hasil yang dicapai (dari yang dilakukan dan diharapkan). Dari definisi tersebut maka prestasi belajar adalah penguasaan pengetahuan dan ketrampilan yang dikembangkan oleh mata pelajaran, yang lazimnya ditujukan dengan nilai-nilai atau angka-angka yang diberikan oleh negara.(Wati, 2016). Bahwa belajar merupakan proses perubahan dari belum mampu menjadi sudah mampu dan terjadi dalam jangka waktu tertentu.(Yusrizal, 2016).

\section{METODE PENELITIAN}

Metode penelitian adalah beberapa langkah yang ditempuh dengan mengumpulkan berbagai informasi berupa data untuk pemecahan masalah dan menemukan jawaban dari masalah yang terjadi. Metode penelitian yang digunakan untuk melakukan penelitian adalah metode grounded (grounded research). Menurut (Sugiyono, 2013) Metode yang diterapkan adalah grounded research yaitu metodologi yang umum untuk mengembangkan suatu teori. Grounded Research merupakan salah satu lingkup dalam penelitian kualitatif yaitu penelitian yang dilakukan dengan wawancara mendalam dan juga pengalaman dari subjek penelitian. Grounded Research dapat disebut juga sebuah pendekatan yang refleksif dan terbuka, dimana pengumpulan data, pengembangan konsep-konsep teoritis dan ulasan literatur berlangsung dalam proses siklus berkelanjutan. Tahap - tahap pengembangan model waterfall adalah sebagai berikut:

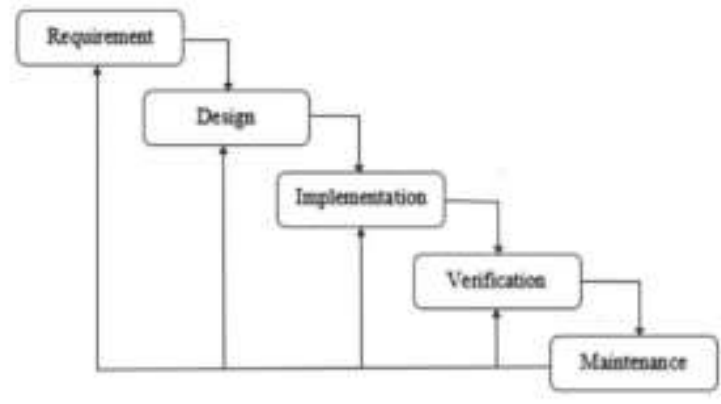

Gambar 1. Metode Waterfall

Menurut (Darmadi, 2013) Metode penelitian adalah suatu cara ilmiah untuk mendapatkan data dengan tujuan kegunaan tertentu. Cara ilmiah berarti kegiatan penelitian itu didasarkan pada ciri-ciri keilmuan yaitu rasional, empiris, dan sistematis. Berdasarkan pemaparan di atas dapat disimpulkan bahwa metode penelitian adalah suatu cara ilmiah untuk memperoleh data dengan tujuan dan kegunaan tertentu. 
Menurut (Prof. Dr. A Muri Yusuf, 2017) Grounded Theory juga dapat disebut sebuah pendekatan yang refleksif dan terbuka, dimana pengumpulan data, pengembangan konsep-konsep teoritis dan ulasan literatur berlangsung dalam proses siklis berkelanjutan. Aspek yang membedakan Grounded Theory dibandingkan dengan pendekatan lain adalah:

1) Peneliti mengikuti prosedur analisis sistematik dalam sebagian besar pendekatan.

2) Grounded Theory lebih terstruktur dalam pengumpulan data dan analisisnya, peneliti memasuki proses riset dengan membawa sedikit mungkin asumsi, peneliti tidak semata-mata bertujuan untuk menguraikan atau menjelaskan, tetapi mengonseptualisasikan. Peneliti berupaya keras untuk menghasilkan dan mengembangkan teori.

3) Disiplin ilmu yang mempengaruhi Grounded Theory adalah sosiologi, terutama mazhab interaksionisme simbolik.

Interaksionisme simbolik berfokus pada interaksi antar manusia, dan berusaha memahami bagaimana individu menafsirkan bahasa dan perilaku orang lain, bagaimana orang-orang memberikan makna bagi pemikiran dan tindakannya sendiri. Anggapan teoritis dan metodologis dari interaksionis simbolik tentang dunia dan cara mempelajarinya terefleksikan dari praktik-praktik Grounded Theory.

\section{HASIL DAN PEMBAHASAN}

Dengan melihat permasalahan yang ada pada SDIT Daarul Fataa dalam pengolahan data Pendaftaran, E-Raport dan Prestasi Siswa. Maka dari itu penulis membuat sistem informasi Pendaftaran, E-Raport dan Prestasi Siswa.

Berikut adalah Sistem Informasi Pendaftaran, ERaport dan Prestasi Siswa SDIT Daarul Fataa yang menggunakan perancangan DFD (Data Flow Diagram)

Diagram Konteks Sistem yang Diusulkan

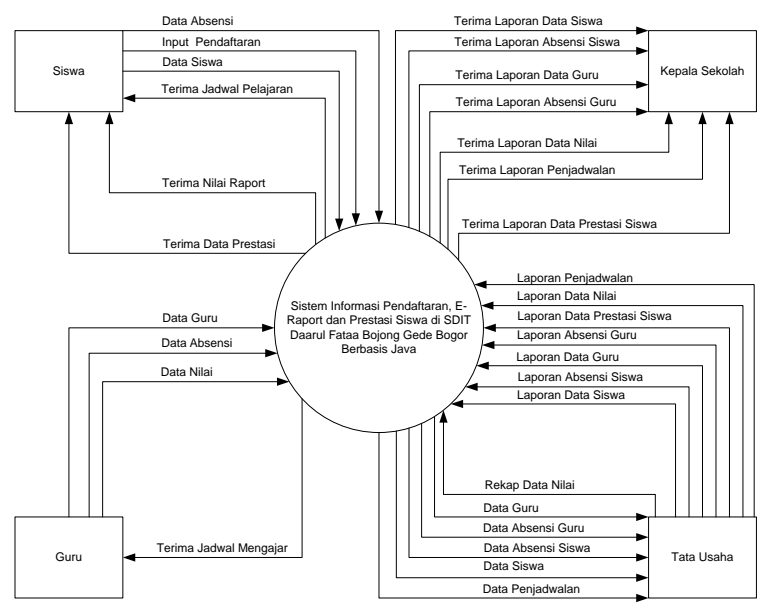

Gambar 2. Diagram Konteks Sistem Yang Diusulkan

\section{Diagram Nol Sistem Yang Diusulkan}

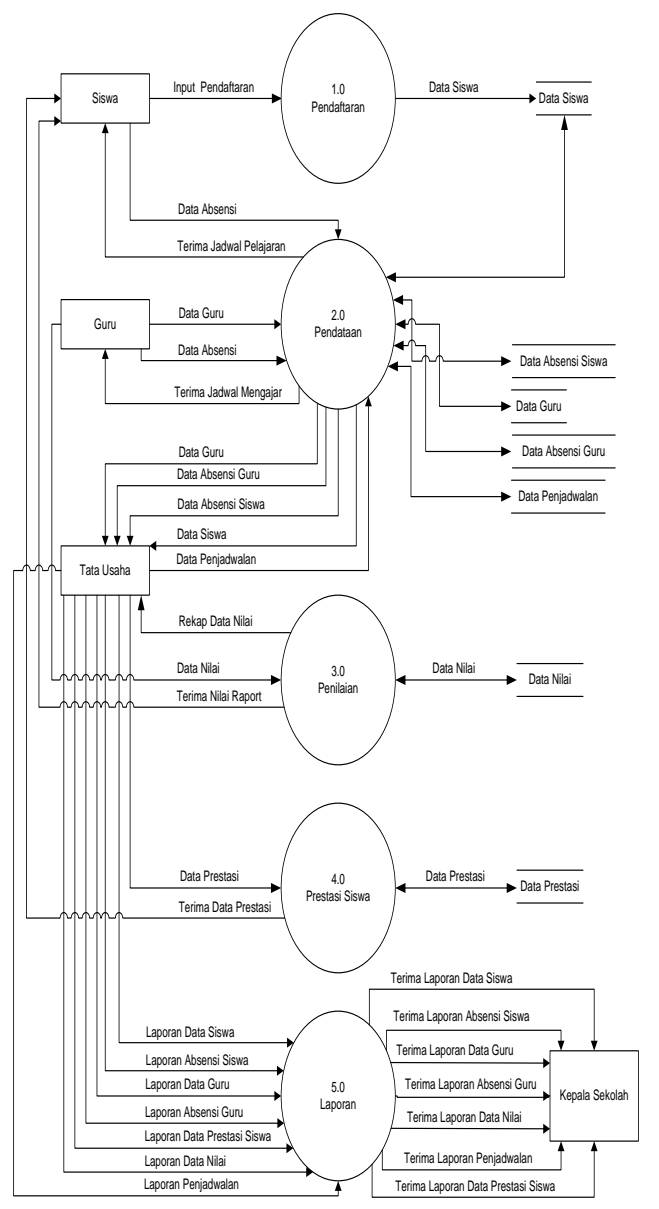

Gambar 3. Diagram Nol Sistem Yang Diusulkan

Entity Relationship Diagram 


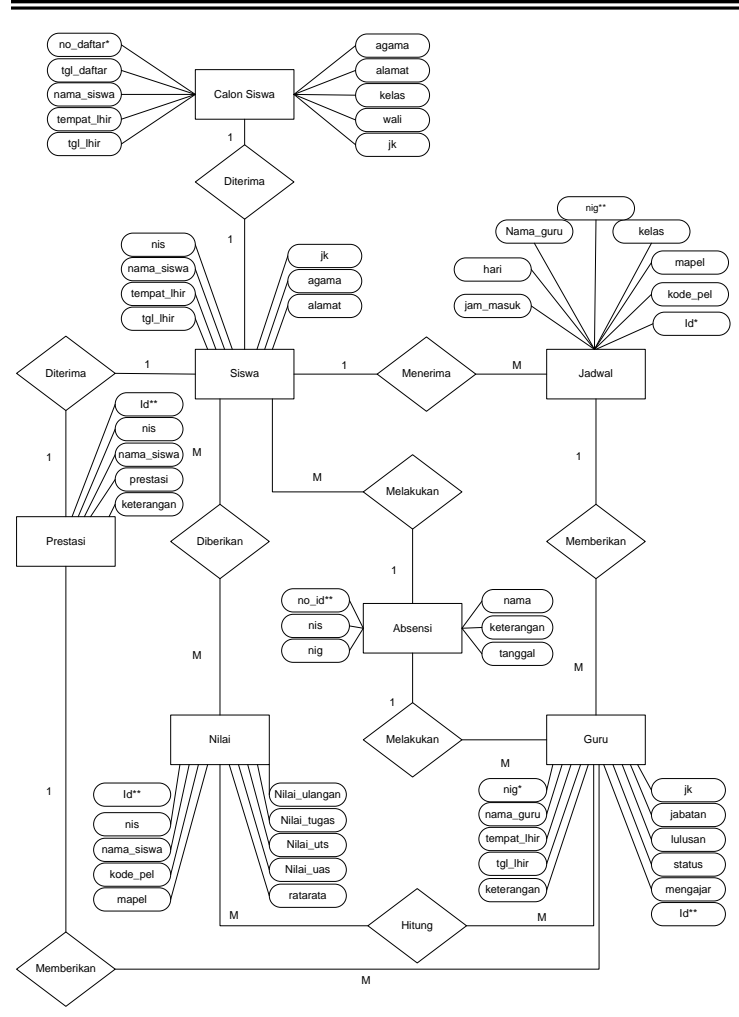

Gambar 4. Entity Relationship Diagram (ERD)

\section{Tampilan Layar}

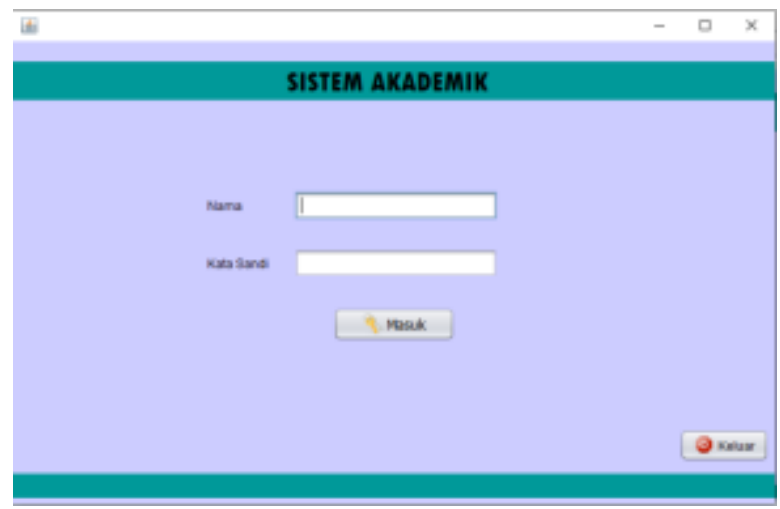

Gambar 5. Tampilan Login

Pada tampilan layar diatas menampilkan menu login pada awal program.

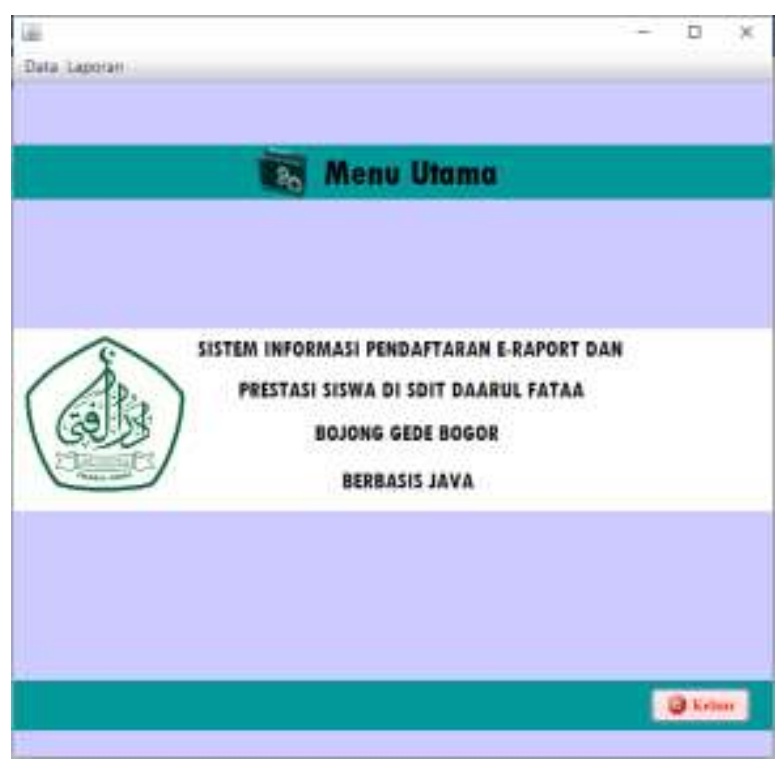

Gambar 6. Tampilan Menu Utama

Tampilan Menu Awal yang dibuat, terdapat menu aplikasi yang nantinya jika ingin menekan pada tombol menu data maka akan ada pilihan berupa menu form siswa, form guru, form prestasi siswa, absensi siswa, absensi guru, form nilai dan exit.

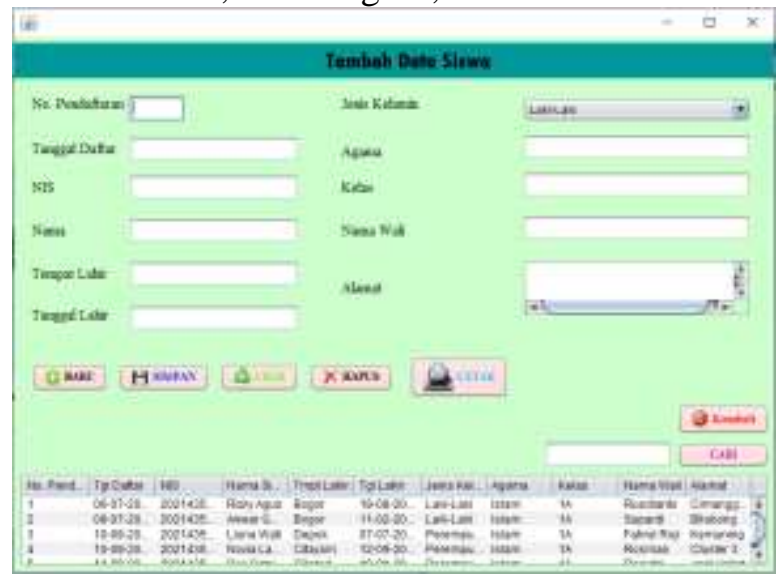

Gambar 7. Tampilan Menu Formulir Data Siswa

Tampilan layar diatas form Data Siswa digunakan untuk mengisi data dengan cara mengisi field-field yang sudah tersedia. 


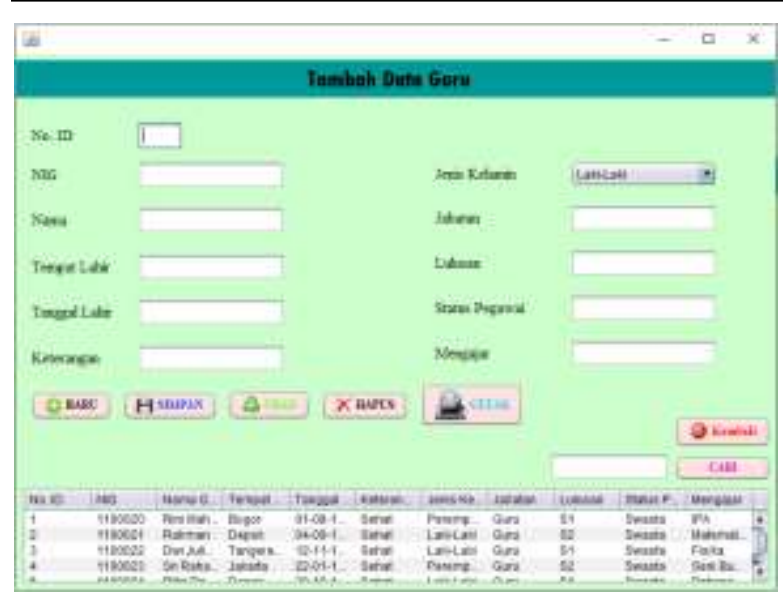

Gambar 8. Tampilan Form Data Guru

Pada tampilan layar diatas form Data Guru digunakan untuk mengisi data guru dengan cara mengisi field-field yang sudah tersedia.

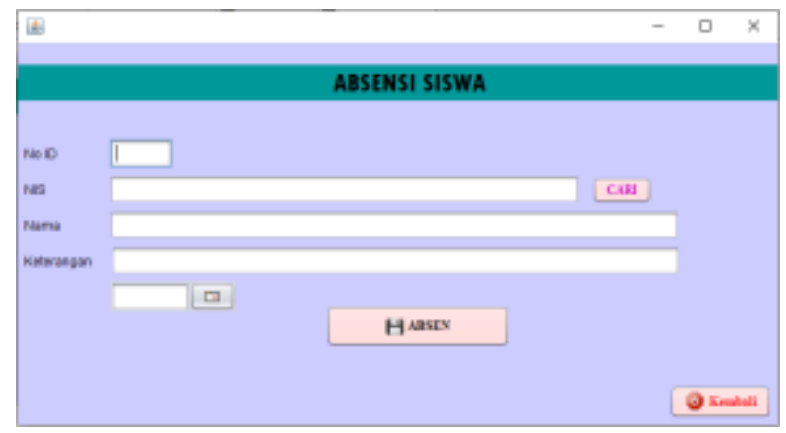

Gambar 9. Tampilan Menu Form Absensi Siswa

Pada tampilan layar diatas form absensi siswa digunakan untuk menginput absensi siswa dengan cara mengisi field-field yang sudah tersedia lalu klik tombol absen.

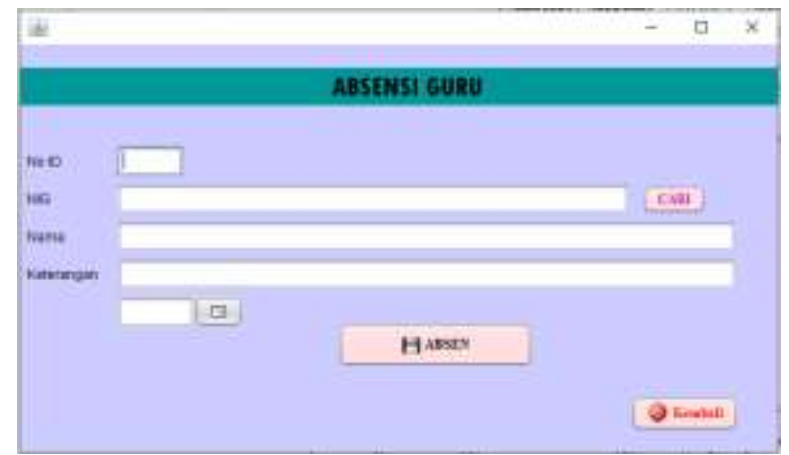

Gambar 10. Tampilan Menu Form Absensi Guru

Pada tampilan layar diatas form absensi guru digunakan untuk menginput absensi guru dengan cara mengisi field-field yang sudah tersedia lalu klik tombol absen.

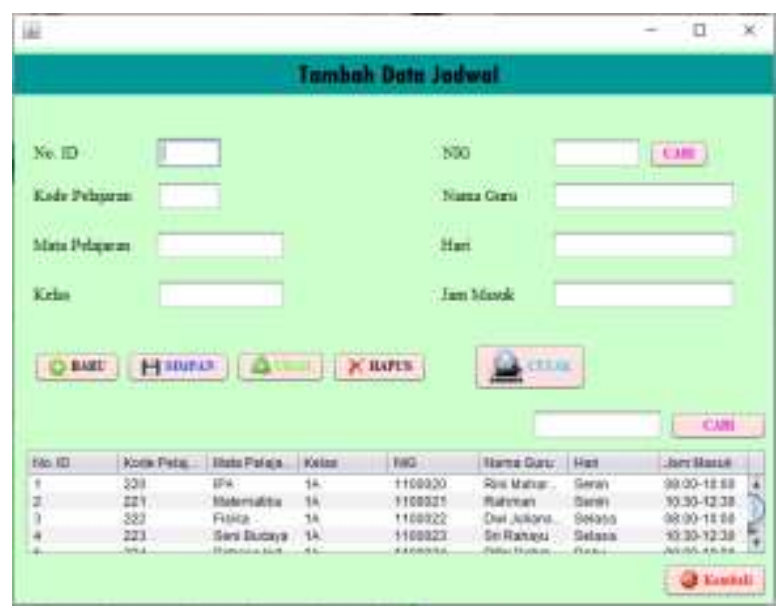

Gambar 11. Tampilan Menu Form Data Jadwal

Pada tampilan layar diatas form Data Jadwal digunakan untuk memasukan data jadwal dengan cara mengisi field-field yang sudah tersedia.

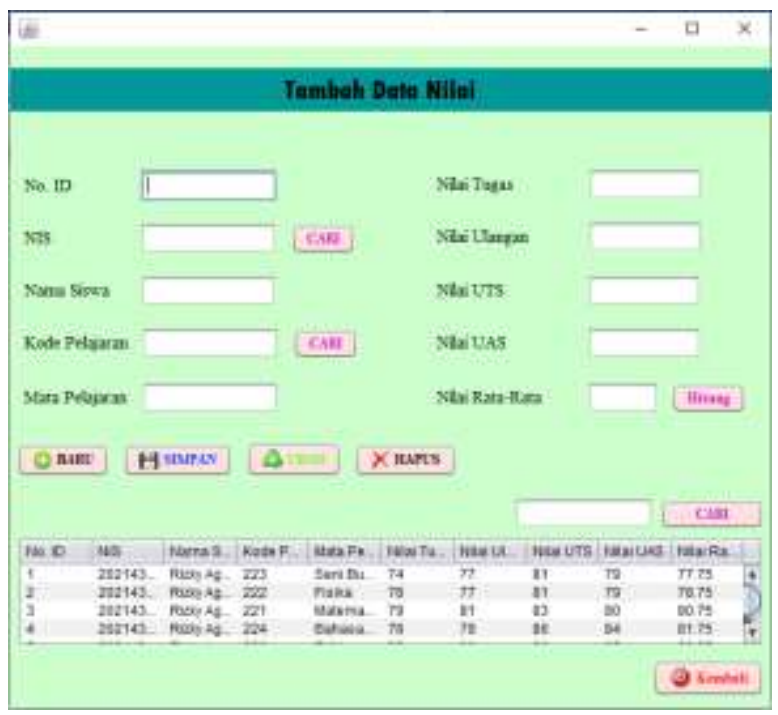

Gambar 12. Tampilan Menu Form Data Nilai Siswa

Pada tampilan layar diatas form Data Nilai Siswa digunakan untuk memasukan data nilai siswa dengan cara mengisi field-field yang sudah tersedia. Dan bisa menyimpan, mengedit,dan menghapus data nilai siswa yang sudah terinput. 


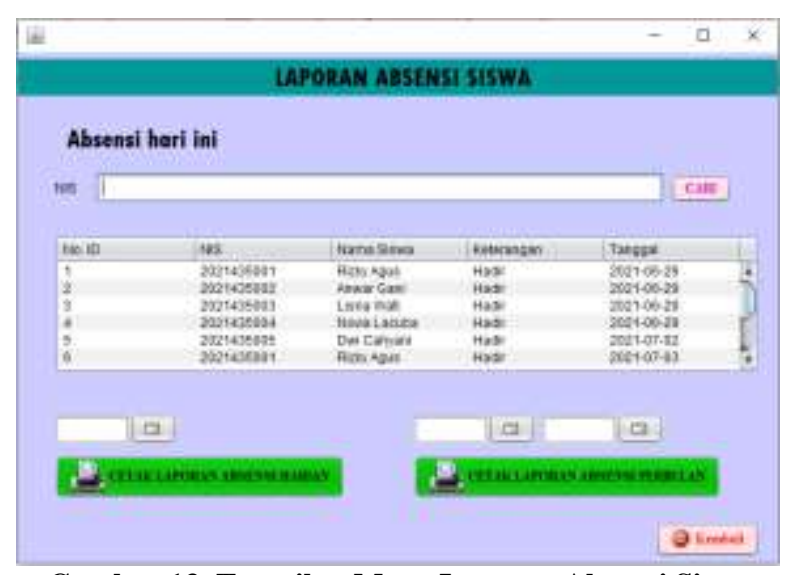

Gambar 13. Tampilan Menu Laporan Absensi Siswa

Pada Tampilan layar diatas adalah Menu Laporan Absensi Harian Siswa dan Bulanan yang digunakan sebagai rekapan harian dan bulanan absensi siswa setiap hari dan bulannya.

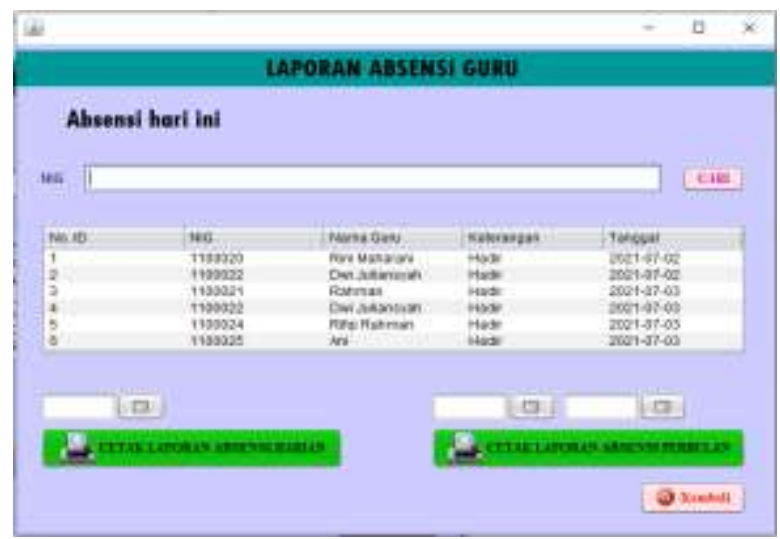

Gambar 14. Tampilan Menu Laporan Absensi Guru

Pada Tampilan layar diatas adalah Menu Laporan Absensi Harian Guru dan Bulanan yang digunakan sebagai rekapan harian dan bulanan absensi guru setiap hari dan bulannya.

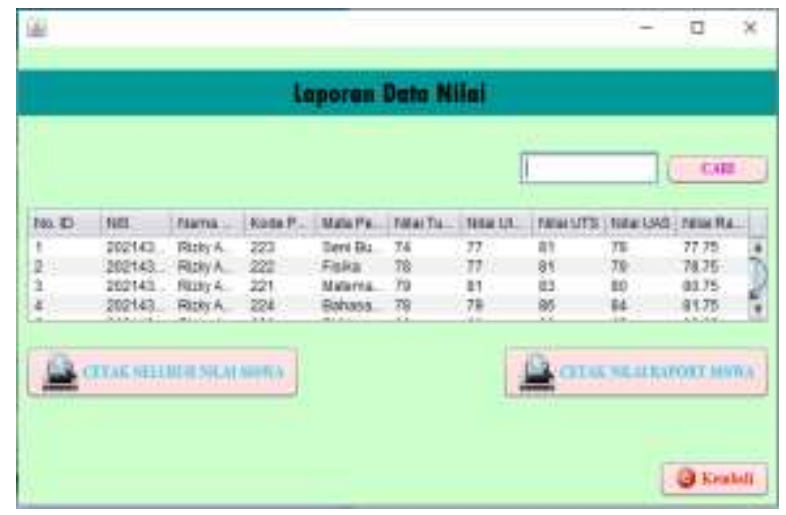

Gambar 15. Tampilan Menu Laporan Data Nilai
Pada Tampilan layar diatas adalah Menu Laporan Nilai seluruh siswa dan Nilai raport persiswa yang digunakan sebagai rekapan nilai persemesternya.

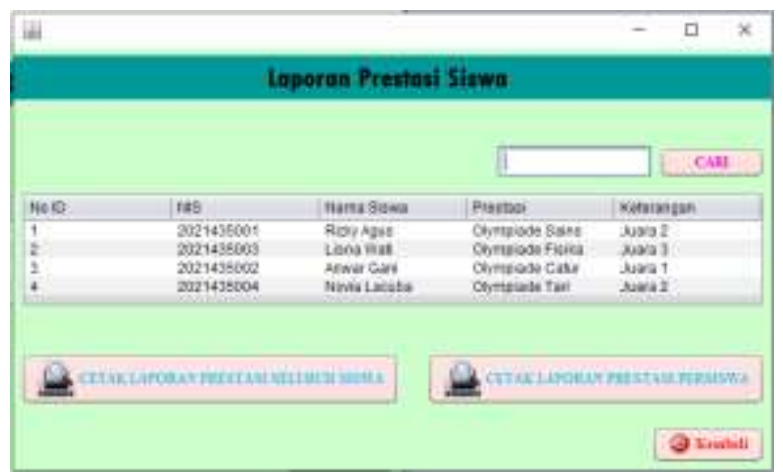

Gambar 16. Tampilan Menu Laporan Prestasi Siswa

Pada Tampilan layar diatas adalah Menu Laporan Prestasi Siswa dan prestasi persiswa yang digunakan sebagai rekapan prestasi siswa setiap ada penghargaan siswa yang diraih.

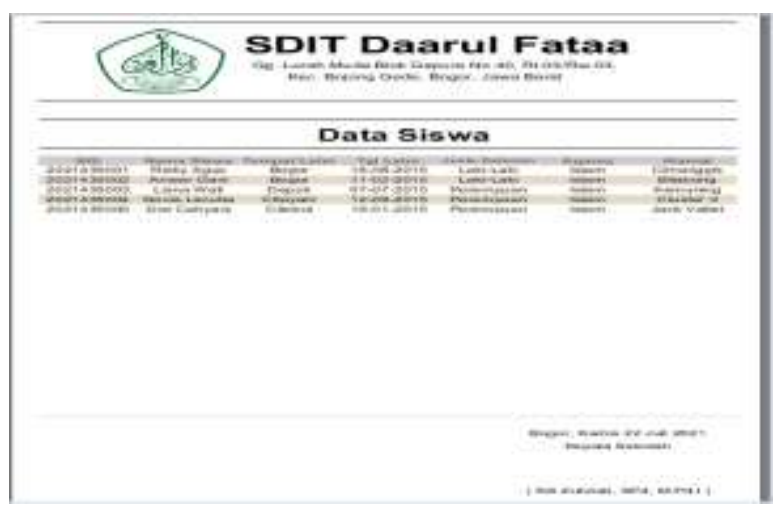

Gambar 17. Tampilan Laporan Data Siswa

Pada Tampilan layar diatas adalah Laporan Data Siswa pada SDIT Daarul Fataa.

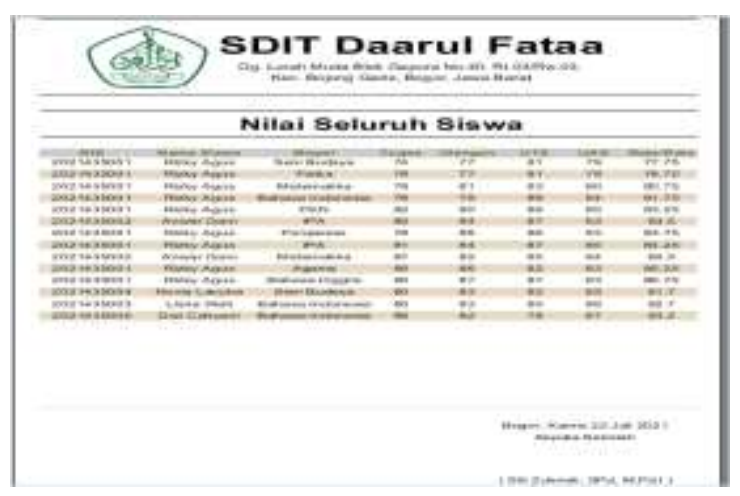

Gambar 18. Tampilan Lapoan Nilai Seluruh Siswa 
Pada Tampilan layar diatas adalah Laporan Data Nilai Seluruh Siswa pada SDIT Daarul Fataa.

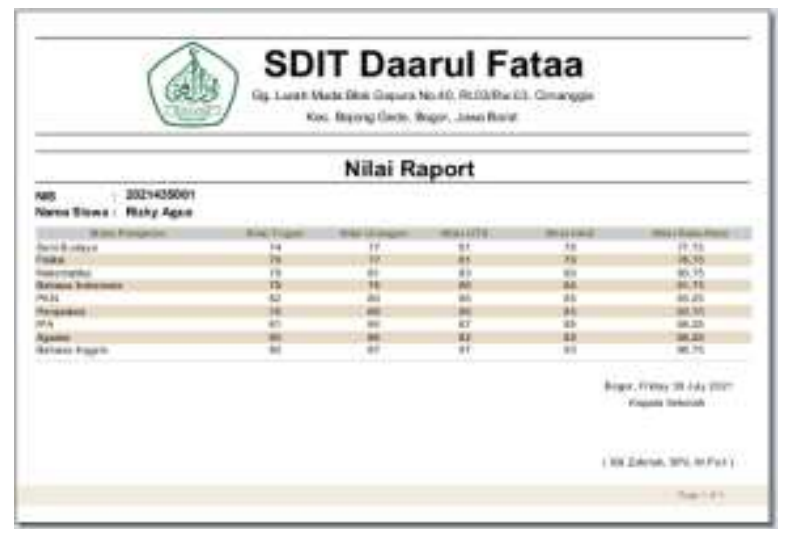

Gambar 19. Tampilan Laporan Nilai Raport Siswa

Pada Tampilan layar diatas adalah Laporan Data Nilai Raport Persiswa pada SDIT Daarul Fataa.

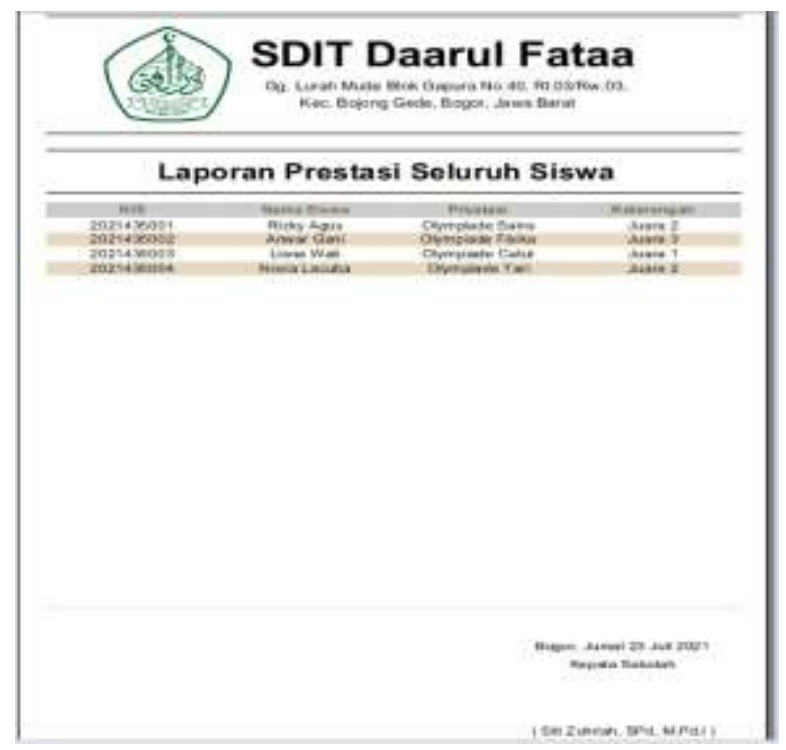

Gambar 20. Tampilan Laporan Prestasi Seluruh Siswa

Pada Tampilan layar diatas adalah Laporan Data Prestasi Seluruh Siswa pada SDIT Daarul Fataa.

\section{SIMPULAN DAN SARAN}

Dengan dibuatnya Sistem Informasi Pendaftaran, Absensi, Raport dan Prestasi Siswa semua kerjaan yang berkaitan dengan Pendaftaran, E-Raport dan Prestasi Siswa dapat berjalan dengan semestinya dan juga efisien. Dalam Sistem ini, bagian yang melakukan pendataan dapat mengerjakan pengisian data - datanya dengan akurat, cepat dan fleksibel serta dapat di update dengan mudah. Dan adanya sistem yang penulis buat ini diharapkan mempermudah dalam kegiatannya dan kecepatan ketetapan informasi yang diberikan. Saran terhadap penelitian yang penulis kerjakan dapat membantu, mempermudah, mempercepat dan tidak terjadinya keterlambatan pembuatan laporannnya.

\section{DAFTAR PUSTAKA}

Darmadi, H. (2013). Metode Penelitian Pendidikan Dan Pengembangan. In Bandung.

Karim, A., \& Purba, E. (2019). Sistem Informasi Pengolahan Data Nilai Berbasis Web. Seminar Nasional Teknologi Komputer \& Sains (SAINTEKS), 856-862. http://seminarid.com/prosiding/index.php/sainteks/article/ view/242/236

Prof. Dr. A Muri Yusuf, M. P. (2017). Metode Penelitian Kuantitatif, kualitatif, \& Penelitian Gabungan. In Kencana (Vol. 4, Issue 3).

Sugiyono. (2013). Metode penelitian pendidikan:(pendekatan kuantitatif, kualitatif dan R \& D). In Bandung: Alfabeta. Sutinah, E., Azima, G. N., \& Imaduddin, E. F. (2018). Sistem Informasi Monitoring Akademik Dan Prestasi Siswa Dengan Metode Waterfall. Journal of Information Engineering and Educational Technology, 2(1). https://doi.org/10.26740/jieet.v2n1.p47-59

Utomo, P., \& Ariyanti, D. (2014). Sistem Informasi Pembayaran dan Pendaftaran Siswa Baru Berbasis Web. Jurnal Sisfotek Global, Vol. 4(No. 2).

Wati, E. R. (2016). Ragam Media Pembelajaran. In PT Kata Pena.

Widiyaningtyas, T. (2013). Sistem Informasi Nilai Rapor Siswa Berbasis Web. EJournal Universitas Malang, Vol 20, No.

Yulianti, L. (2017). Sistem Informasi Pendaftaran Siswa Baru. In Jurnal Ekonomi Volume 18, Nomor 1 Maret201 (Vol. 2, Issue 1).

Yusrizal. (2016). Pengukuran \& Evaluasi Hasil dan Proses Belajar. In Pale Media Prima: Vol. Pertama (Issue Oktober 2016). 